\title{
Articaine VS Lignocaine in Orthodontic Extraction of Maxillary Premolars - A Randomized, Double-Blinded Study
}

\author{
Meenu Jain ${ }^{1}$, Namrata Dogra², Manish Gupta ${ }^{3}$, Seema Grover ${ }^{4}$ \\ ${ }^{1,3}$ Gupta Super Speciality Dental Hospital, Gandhi Nagar, Jind, Haryana, India, 2,4 Department of \\ Orthodontics, SGT University, Gurugram, Haryana, India,
}

\section{ABSTRACT}

\section{BACKGROUND}

Local anaesthetics helps in preventing pain during surgical and dental procedures by blocking the peripheral nerves. The primary objective of this investigation was to compare and evaluate $4 \%$ articaine hydrochloride (with $1: 100000$ adrenaline) and $2 \%$ lignocaine hydrochloride (with $1: 80000$ adrenaline) in terms of pulpal anaesthesia, volume of anaesthetic solution administered, need of re-anaesthesia and difficulty of extraction during orthodontic extraction of maxillary first premolars.

\section{METHODS}

This prospective randomized, double-blinded study was conducted on 43 patients of less than 40 years of age requiring bilateral maxillary first premolar extractions for orthodontic purposes. Each patient was randomly assigned to receive either $2 \%$ lignocaine hydrochloride or $4 \%$ articaine hydrochloride for premolar extraction of one side and other solution was administered for premolar extraction of contralateral side spaced 1 to 3 weeks apart. In each patient, the difference in pulpal anaesthesia, volume of anaesthetic solution administered, need of re-anaesthesia, difficulty of extraction and duration of anaesthesia was assessed on administration of lignocaine hydrochloride and articaine hydrochloride.

\section{RESULTS}

Statistically significant difference in pulpal anaesthesia levels was found when the articaine and lignocaine groups $(\mathrm{P}>0.05)$ were compared, with a higher mean pulpal anaesthesia among the articaine group. There was no difference in volume of anaesthetic solution administered on buccal and palatal side among the articaine and lignocaine groups. Only $2.3 \%$ of patients in both the groups required re-anaesthesia on the buccal side. There was no significant difference in difficulty of extraction in both the groups. The articaine group had a longer mean duration of anaesthesia as compared to the lignocaine group which was highly significant.

\section{CONCLUSIONS}

Articaine may be used to replace lignocaine in orthodontic extraction of maxillary premolars with clinical advantages like higher pulpal anaesthesia and longer duration of anaesthesia.

\section{KEY WORDS}

Local Anaesthetic, Lignocaine Hydrochloride, Articaine Hydrochloride, Orthodontic Extraction, Prospective Study, Double-Blinded Study.
Corresponding Author: Dr. Namrata Dogra, Department of Orthodontics, SGT University, Gurugram, Haryana - 122505, India. E-mail:

namrata.dogra@sgtuniversity.org

DOI: 10.14260/jemds/2021/607

How to Cite This Article:

Jain M, Dogra N, Gupta M, et al. Articaine vs lignocaine in orthodontic extraction of maxillary premolars - a randomized, double-blinded study. J Evolution Med Dent Sci 2021;10(35):2969-2974, DOI: $10.14260 /$ jemds/2021/607

Submission 21-04-2021,

Peer Review 30-06-2021,

Acceptance 05-07-2021,

Published 30-08-2021.

Copyright (C) 2021 Meenu Jain et al. This is an open access article distributed under Creative Commons Attribution License [Attribution 4.0 International (CC BY 4.0)] 


\section{BACKGROUND}

In dental procedures, effective control of pain is the utmost requirement. There are various methods used to control pain in dentistry, among which use of local anaesthetic agent is the commonly employed technique. The ability to provide safe, effective local anaesthesia is the corner stone of successful clinical and surgical practice. Local anaesthetics form the backbone of pain control techniques in dentistry. Prior to their introduction, general anaesthesia, was the only viable method of managing surgical pain. Administration of drugs that depressed the central nervous system to the point that the patient loses consciousness allowed the surgeon to successfully complete the otherwise painful and potentially lethal procedures.

However, general anaesthesia has its own significant adverse effects. Local anaesthetics block the peripheral nerves and are used to prevent pain, during surgical and dental procedures. ${ }^{1}$ In 1859 , the first local anaesthetic agent, cocaine was isolated by Niemann. Since the introduction of the cocaine, local anaesthesia, and the subsequent development of the procaine and other related anaesthetics, dentistry has prided itself on being as close to "painless" as possible. The lidocaine was developed by Nils Lofgren in 1943 and in 1948 it was marketed with the name of Xylocaine. The initial amide local anaesthetic, lidocaine or properly known as the xylocaine, revolutionized pain control and became the gold standard. This local anaesthetic became the choice of all dentists.

The key benefits of the lidocaine were its shorter onset of action and longer duration of anaesthesia as compared to the esters. $^{2}$ In succeeding years, other amide local anaesthetics such as mepivacaine, prilocaine, bupivacaine, and etidocaine were introduced. These popular drugs proved to be more rapid acting than older ester - type drugs. Rusching and colleagues prepared Carticaine in 1969 and in 1976 its name was changed to articaine. ${ }^{3}$ Articaine instantly became so popular in many countries due to its excellent efficacy.

Articaine differs from the previous amide local anaesthetic in being that it was derived from a thiophene ring instead of the usual benzene ring which gives the molecule better diffusion properties as compared to lidocaine. It has a half-life of 90 minutes due to presence of additional ester group which is hydrolysed by plasma esterase. This makes re-injection of articaine safer.1,4 Articaine can be considered superior than other local anaesthetic agents as it has better soft tissue and bone diffusion, faster onset of block, high anaesthesia quality, and low toxicity.

The concentration of articaine in the alveolus of a tooth in the upper jaw after extraction was about 100 times higher than systemic circulation. In dentistry, $4 \%$ articaine with adrenaline $5 \mu \mathrm{g} / \mathrm{ml}$ is widely used for infiltration and conduction anaesthesia. Biotransformation of articaine occurs in both the plasma (hydrolysis by plasma esterase) and the liver (hepatic microsomal enzymes). This study aimed to evaluate and compare $4 \%$ articaine and $2 \%$ lignocaine in terms of pulpal anaesthesia, volume of anaesthetic solution administered, need of re-anaesthesia and difficulty of extraction in bilateral extraction of maxillary premolars for orthodontic purposes.

\section{METHODS}

This prospective randomized, double-blinded study was conducted on 43 patients (28 females and 15 males), aged less than 40 years who reported for bilateral orthodontic extractions of upper premolar teeth to the department of oral and maxillofacial surgery from February 2013 to September 2014. Sample size was calculated using the findings of Lombardo et al. Keeping $\alpha=0.05$ and power of study as $99 \%$, sample size of 40 subjects was required. Hence, 43 patients were selected.

\section{Inclusion and Exclusion Criteria}

The participants were selected under the following criteria age less than 40 years, American Society of Anaesthesiologists (ASA) Grade - I patients (a healthy individual with no systemic disease), having co-operative behaviour for dental treatment under local analgesia. ${ }^{5}$ But the participants who were excluded from the study under the following criteria were - Medically compromised patients, pregnancy, history of allergy to lignocaine/articaine or any of the constituents in local anaesthetic solutions, age more than 40 years, and children below the age of reasoning infection/inflammation near the site of injection, smokers, and alcoholics.

50 cartridges each containing $1.8 \mathrm{ml}$ of $2 \%$ lignocaine $\mathrm{HCl}$ and 50 cartridges each of $1.7 \mathrm{ml}$ of $4 \%$ articaine hydrochloride were masked by coloured tapes of two different color (blue and green) by the independent observer to prevent identification. Randomization codes were held by the staff member who were responsible for giving masked cartridges but had no role in drug administration or in assessing outcomes. Neither the patient nor the surgeon had any knowledge of the identity of the solution so that the doubleblind nature of the trial was ensured. In all patients, a thorough medical history and preoperative radiographs (OPG) were taken. After a brief examination, patients who met all the criteria had the first treatment visit for the extraction of the upper first premolar teeth of one side and were randomly assigned to receive either $2 \%$ lignocaine hydrochloride with 1 : 80000 adrenaline (Lignocaine special, Septodont India private health care) or $4 \%$ articaine hydrochloride with 1 : 100000 adrenaline (Septanest, Septodont India private health care) for the first procedure and the other solution was administered for the extraction of upper first premolar of contralateral sides at no less than one week (to eliminate possible carry - over effects) and not greater than three-week interval. Before administration of local anaesthetics at both appointments, electric pulp testing was done in the tooth to be extracted and the contralateral canine (control) with the electric pulp tester to obtain baseline information. The electrode was inserted in the corner of the mouth of the patient and the patient was asked to raise his/her hand in case sensations were felt. The number associated with the initial sensation was recorded to obtain the baseline reading.

A standard maxillary infiltration injection containing either of the two solutions, $0.8 \mathrm{ml}$ solution of $1.7 \mathrm{ml}$ of $4 \%$ articaine hydrochloride or $1.8 \mathrm{ml}$ of $2 \%$ lignocaine hydrochloride was administered in the buccal vestibule using a self - aspirating syringe with $30-G$ needle $[(.31 \mathrm{~mm} \times 25 \mathrm{~mm})$ DENJECT disposable needle 30G - L ]. 


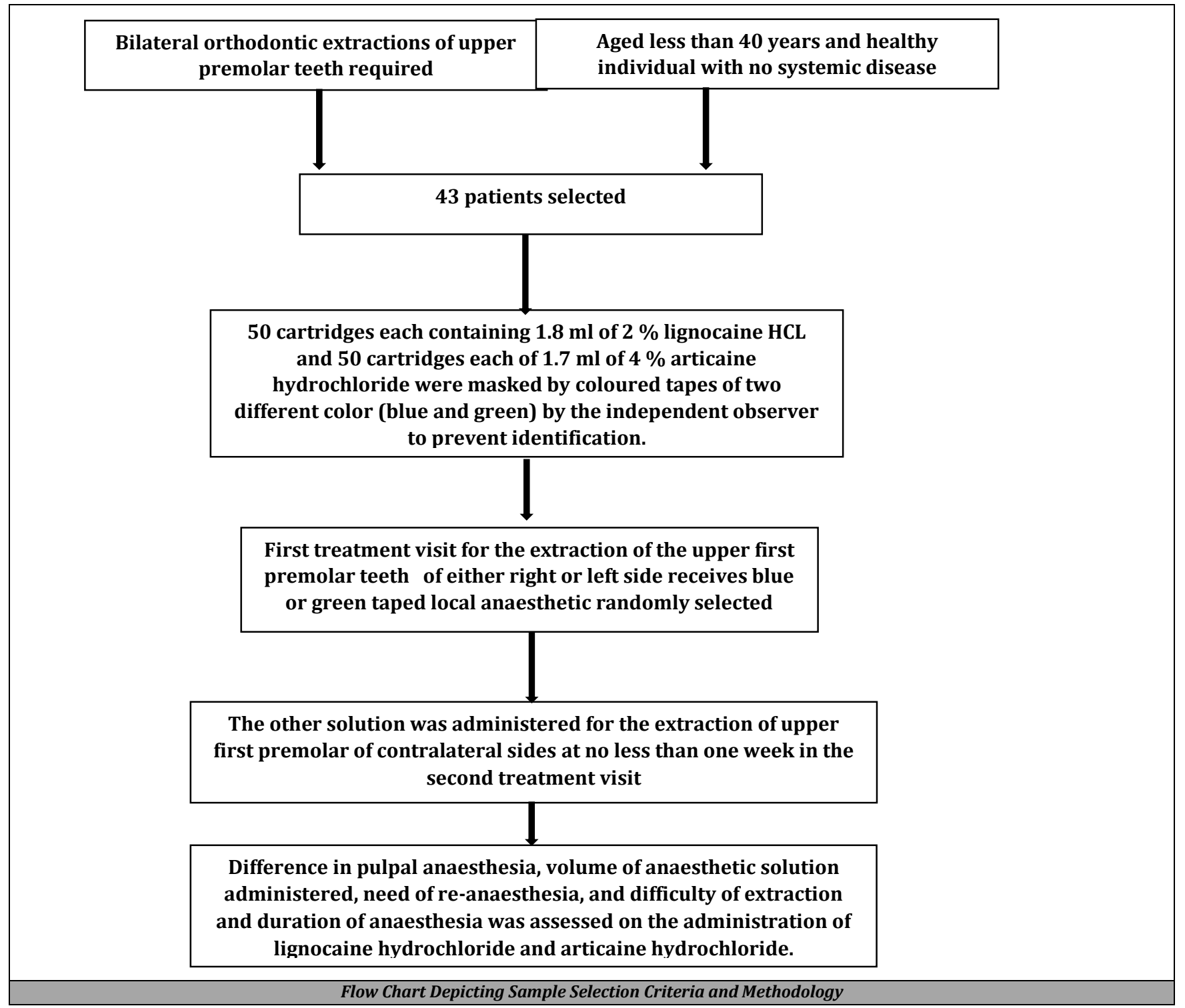

Palatal infiltration was administered 10 minutes after buccal infiltration when it was observed that palatal anaesthesia was not achieved with buccal injection. If the patient complained of pain on the buccal or palatal side, then the need for re-anaesthesia was considered. Simultaneously electric pulp testing was done every 1, 3, 5, 7 and 9 minutes to observe the onset of pulpal anaesthesia After palatal injection, the onset of palatal anaesthesia was checked on every 30 seconds till 10 minutes until no response was observed and similarly pulp testing was done on every 1 minute, 3 minutes, 5 minutes, 7 minute and 9 minute to note the onset of pulpal anaesthesia. After successful anaesthesia had been achieved, the tooth was extracted using a standard forceps' technique under sterile aseptic conditions and a pressure pack was placed. Post-operative instructions were given and only analgesics (Tab. 1 Ibugesic plus TDS $\times 3$ days) was prescribed. Difficulty of extraction was recorded by the surgeon on a selfmade 2-point category scale mentioned below:
2. Complicated (dilacerated roots, multiple roots, fracture of root / buccal cortical plate, need for surgical procedure)

The duration of anaesthesia was also measured. Patient marked fliers distributed to them representing the loss of intensity of heaviness $(++++++$ to -$)$, as the time elapsed from 30 minutes to 6 hours, after extraction, of 15-minute interval. This was also confirmed by a telephone conversation with the patient. Post-operative complications if present were observed.

\section{Statistical Analysis}

The data were entered in the Microsoft Excel spreadsheet 2013. Student's unpaired t-test analysis was performed using IBM Statistical Package for Social Sciences (SPSS version 24.0) (Armonk, NY: IBM Corp.). Paired t-test was used for comparison of mean pulpal anaesthesia between the two groups. Chi square test was used to investigate whether distributions of categorical variables differ from one another. $P$ value $<0.05$ was considered as statistically significant. 
resulted in pain in asymptomatic teeth. ${ }^{12}$ Therefore it is important to perform electronic pulp testing on vital teeth to ensure pulpal anaesthesia. Hass et al. also described the reading of 80 on the pulp tester as the criteria for pulpal anaesthesia in accordance to above studies. ${ }^{13}$ We however, in our study did not achieve this reading in both the solutions groups.

Difficulty of extraction was assessed by the surgeon. 83.7 $\%$ of extractions among the blue (articaine) group and $88.4 \%$ in the green (lignocaine) group were assessed by the surgeon to be simple where as $16.3 \%$ in blue group and $11.6 \%$ in green group extraction was assessed complex.

In this study, mean duration of anaesthesia achieved with the articaine group was longer than that achieved with the lignocaine group. Similar results were reported by Rebolledo et al. and Bansal et al. ${ }^{44,15}$ The duration of the effect of an anaesthetic depends upon its protein binding degree. The duration of the effect of the local anaesthetic is also affected by the injection site or concentration of vasoconstrictor present in the anaesthetic solution. Among all amide local anaesthetics, Articaine has highest protein binding percentage. This in turn implies a longer duration of the anaesthetic effect. Articaine has potential to cause methaemoglobinemia, neuropathies, paraesthesia, hypersensitivity, and allergy. Headache, gingivitis and facial oedema were the most commonly reported adverse events in the articaine group. It was noted that the paraesthesia resolved in all the involved patients. The incidence of adverse events was similar in lignocaine group. No adverse effects were observed in our study. Thus, articaine can be considered as an alternative to other local anaesthetic agents.

\section{CONCLUSIONS}

Higher level of pulpal anaesthesia was achieved with $4 \%$ articaine as compared to $2 \%$ lignocaine, indicating that articaine provides adequate analgesia for the procedure to be performed. There was no difference in volume of anaesthetic solution administered on buccal and palatal side among the articaine and lignocaine groups. Only $2.3 \%$ of patients in both the groups required re-anaesthesia on the buccal side. There was no significant difference in difficulty of extraction in both the groups. $4 \%$ articaine with 1 : 100,000 epinephrine was found to have a longer duration of action than $2 \%$ lignocaine with $1: 80,000$ epinephrine, thus adding to the patient comfort after the extractions by increasing the pain-free duration. This difference was statistically highly significant. Thus, for orthodontic extraction of maxillary premolars, articaine can be a local anaesthetic of choice.

\section{Future Scope}

Further controlled clinical trials with similar local anaesthetic agents in other areas of the oral cavity in the form of infiltration and nerve block are necessary to evaluate the safety and efficacy of articaine.

Data sharing statement provided by the authors is available with the full text of this article at jemds.com.

Financial or other competing interests: None.

Disclosure forms provided by the authors are available with the full text of this article at jemds.com.
Authors acknowledge the immense help received from the scholars whose articles are cited and included in references to this manuscript.

\section{REFERENCES}

[1] McLure HA, Rubin AP. Review of local anaesthetic agents. Minerva Anestesiol 2005;71(3):59-74.

[2] Malamed SF. Local anesthetics: dentistry's most important drugs, clinical update 2006. J Calif Dent Assoc 2006;34(12):971-6.

[3] Malamed SF, Gagnon S, Leblanc D. Efficacy of articaine: a new amide local anaesthetic. J Am Dent Assc 2000;131(5):635-42.

[4] Malamed SF, Gagnon S, Leblanc D. A comparison between articaine $\mathrm{HCl}$ and lidocaine $\mathrm{HCl}$ in pediatric dental patients. Pediatr Dent 2000;22(4):307-11.

[5] Daabiss M. American Society of Anaesthesiologists physical status classification. Indian $\mathrm{J}$ Anaesth 2011;55(2):111-5.

[6] Moore PA, Boynes SG, Hersh EV, et al. The anesthetic efficacy of 4 percent articaine 1:200,000 epinephrine: two controlled clinical trials. J Am Dent Assoc 2006;137(11):1572-81.

[7] Elad S, Admon D, Kedmi M, et al. The cardiovascular effect of local anesthesia with articaine plus 1:200,000 adrenalin versus lidocaine plus 1:100,000 adrenalin in medically compromised cardiac patients: a prospective, randomized, double blinded study. Oral Surg Oral Med Oral Pathol Oral Radiol Endod 2008;105(6):725-30.

[8] Jastak JT, Yagiela JA. Vasoconstrictors and local anesthesia: a review and rationale for use. J Am Dent Assoc 1983;107(4):623-30.

[9] Sreekumar K, Bhargava D. A prospective double blind study to assess the latency and efficacy of articaine and lignocaine in surgical removal of impacted mandibular third molars in Indian patients. J Stomat Occ Med 2012;5:10-14.

[10] Dugal A, Khanna R, Patankar A. A comparative study between $0.5 \%$ centbucridine $\mathrm{HCl}$ and $2 \%$ lignocaine $\mathrm{HCl}$ with adrenaline $(1: 2,00,000)$. J Maxillofac Oral Surg 2009;8(3):221-3.

[11] Dreven LJ, Reader A, Beck M, et al. An evaluation of an electric pulp tester as a measure of analgesia in human vital teeth. J Endod 1987;13(5):233-8.

[12] Certosimo AJ, Archer RD. A clinical evaluation of the electric pulp tester as an indicator of local anesthesia. Oper Dent 1996;21(1):25-30.

[13] Haas DA, Harper DG, Saso MA, et al. Comparison of articaine and prilocaine anesthesia by infiltration in maxillary and mandibular arches. Anesth Prog 1990;37(5):230-7.

[14] Rebolledo AS, Molina ED, Aytís LB, et al. Comparative study of the anesthetic efficacy of $4 \%$ articaine versus 2 $\%$ lidocaine in inferior alveolar nerve block during surgical extraction of impacted lower third molars. Med Oral Patol Oral Cir Bucal 2007;12(2):E139-44. 
[15] Bansal SK, Kaura S, Sangha PK, et al. Comparison of anesthetic efficacy of $4 \%$ articaine versus $2 \%$ lignocaine. Indian J Dent Sci 2018;10(2):92-7. 